\title{
SEED DISPERSAL AND RECRUITMENT LIMITATION ACROSS SPATIAL SCALES IN TEMPERATE FOREST FRAGMENTS
}

\author{
Amy B. McEuen ${ }^{1,2}$ And Lisa M. CurRan ${ }^{1,3}$ \\ School of Natural Resources and Environment, 430 E. University, University of Michigan, \\ Ann Arbor, Michigan 48109 USA
}

\begin{abstract}
Despite increasing evidence of seed limitation in forest ecosystems, data remain sparse on spatial patterns of seed rain at large $(>1$ ha) spatial scales. We monitored seed rain $\left(28.5 \mathrm{~m}^{2}\right)$ throughout five northern hardwood forest fragments ( 27 ha sampled across $14-\mathrm{km}^{2}$ area) in southeastern Michigan over two years. Four fragments were nearest neighbors $(300-700 \mathrm{~m})$, yet varied in species composition, providing the opportunity to detect landscape-scale seed exchange. Of the 37 species of woody plants present in the seed rain (98032 mature seeds), only three (Betula papyrifera, Ostrya virginiana, and Ulmus americana) had widespread seed dispersions within all fragments containing resident sources (seed in $>70 \%$ of traps in each fragment). Seed dispersions, measured as the percentage of traps within a fragment receiving seed, differed among species using different dispersal vectors with animal-dispersed species arriving in a lower percentage of seed traps than wind-dispersed seeds. At a given source density, seed dispersions increased with decreasing seed mass. Light-seeded, fecund species such as Betula or Tsuga required lower source densities to saturate fragments with seed compared to heavy-seeded species (Acer, Fraxinus, Tilia). Heavy-seeded wind- and animal-dispersed species also displayed the strongest evidence of seed limitation, with seedling presence significantly associated with presence of seed for Carpinus caroliniana, Fagus grandifolia, Prunus avium, and Tilia americana. Of 17 species, landscape-scale seed exchange was detected for only four disturbance-associated species (Acer negundo, Betula papyrifera, Celastrus scandens, Eleaganus umbellata). No exchange was detected for Acer rubrum, Betula alleghaniensis, or Tsuga canadensis, despite broad seed dispersions $(>50 \%)$ in fragments with resident sources, suggesting the potential for seed limitation for these species at larger spatial scales. Seed encounter probabilities suggest that potential seed competitors often fail to simultaneously colonize microsites. We suggest that all dominant species in northern hardwood forests can be seed limited at some spatial scale and that results are consistent with "winning by forfeit" scenarios of diversity maintenance in forest ecosystems.
\end{abstract}

Key words: Acer rubrum; Betula alleghaniensis; Betula papyrifera; dispersal vector; forest fragmentation; landscape ecology; seed dispersion patterns; seed limitation; seed mass; seedling recruitment; spatial recruitment limitation; Tsuga canadensis.

\section{INTRODUCTION}

Seed dispersal has typically been studied at small spatial scales (Cain et al. 2000). Studies have examined seed rain around either isolated trees or, as models were developed which could account for overlapping seed shadows, within individual forest stands $(<1$ ha, Clark et al. 1998, 1999). Empirical data are lacking on spatial patterns of seed dispersion within larger forest stands (4-10 ha), and seed exchange between isolated forest fragments $(100-500 \mathrm{~m}$ ) has not been quantified (Cain et al. 2000, Nathan and Muller-Landau 2000). Such data are, however, needed both to predict the long-term

Manuscript received 9 January 2003; revised 13 June 2003; accepted 16 June 2003. Corresponding Editor: J. S. Brewer.

${ }^{2}$ Present address: Wilkes University, Biology Department, P.O. Box 111, Wilkes-Barre, Pennsylvania 18766 USA. E-mail:mceuen@wilkes.edu

${ }^{3}$ Present address: Yale School of Forestry and Environmental Studies, 370 Prospect St., New Haven, Connecticut 06511 USA. dynamics of forests in fragmented landscapes, and to determine how trees may "move" through such landscapes in response to climate change (Cain et al. 2000). In addition, understanding the spatial scale of seed availability within forests is increasingly important given evidence of seed limitation in these systems. Seed addition experiments have documented significant relationships between patterns of available seed (i.e., seed densities and dispersions) and seedling densities and dispersions (Ehrlen and Erickson 2000, Turnbull et al. 2000, McEuen 2002). If seed is a primary factor limiting seedling recruitment within forests (seed limitation), it becomes vital that we understand the spatial scales at which seeds are widely available and how these scales may differ among species.

Ecological theory suggests seed limitation and seedling limitation (broadly categorized as recruitment limitation) have important consequences for forests, potentially affecting composition, structure and diversity (e.g., Clark and Yi 1995, Hurtt and Pacala 1995). Forest modeling has shown that overstory dominance of in- 
dividual canopy trees is highly sensitive to changes in seed and seedling dispersal (Ribbens et al. 1994). Recruitment limitation, defined as the failure to have any viable juveniles at an available site (sensu Hurtt and Pacala 1995), can theoretically maintain diversity within ecosystems even in the presence of strong competitive asymmetries between plants and locally deterministic competitive outcomes (Hurtt and Pacala 1995). In such models, recruitment limitation maintains diversity through "winning by forfeit" scenarios, where inferior competitors occupy sites because superior competitors were absent when conditions were appropriate for establishment. Empirical evidence of recruitment limitation is accumulating in tropical forests, where spatial patterns of tree diversity are better explained by when and where seed are available than by canopy gap availability (Hubbell et al. 1999, Curran and Webb 2000). In these systems, gaps influence regeneration by creating opportunities for seedling recruitment. However, the particular species that establish in a given gap is dictated primarily by locally constrained seed pools (Hubbell et al. 1999, Dalling et al. 2002). Although such mechanisms were long assumed not to operate in temperate forests because of their lower tree diversity, overlapping canopy crowns, and higher dominance of individual species, recruitment limitation may be more pervasive in temperate forests than previously assumed (Clark et al. 1998). Several canopy trees of Appalachian forests show spatially restricted seed dispersion patterns (Clark et al. 1998), with animal-dispersed plants in particular having poorly dispersed seed in contrast to wind-dispersed plants. This, coupled with several studies demonstrating seed limitation in temperate forest plants (reviewed in Turnbull et al. 2000), strongly points to the need for comprehensive studies aimed at determining the degree of recruitment limitation in temperate forests. Here we examine large-scale seed dispersion patterns for several temperate trees, shrubs, and vines within northern hardwood forest fragments and determine their relationships to patterns of seedling dispersion across spatial scale.

Our approach was to measure seed sources and seed and seedling dispersions at a large spatial scale throughout several neighboring forest fragments. We selected fragments that varied in plant species composition so that landscape-scale seed exchange could be quantified. Our study design allowed us to test two general predictions regarding seed dispersal and recruitment limitation. First, if seeds play an important role in temperate forests, a necessary condition is that they cannot be universally available across the landscape. Therefore, we predicted that seed distributions would be restricted both within and among forest fragments (i.e., low levels of seed dispersion within fragments and poor seed exchange between fragments). Second, if seed dispersal limits seedling recruitment, then seed and seedling distributions should be spatially correlated (i.e., seedlings should be more likely to occur in areas receiving seed). If seedling recruits are present across the landscape despite restricted seed dispersion patterns, this suggests seeds are more widely available than short-term seed rain sampling would suggest.

Our study addressed five questions: (1) What are the patterns of seed dispersion across the landscape, both within and among individual fragments? (2) Does seed exchange between fragments occur and for which species? (3) What factors (dispersal vector, seed mass, fecundity, source availability) strongly influence seed dispersion patterns? (4) Are seed and seedling dispersion patterns spatially correlated as would be predicted under recruitment limitation? and (5) Do conditions for winning-by-forfeit occur in temperate forests as evidenced by low encounter probabilities of potentially competitive tree seeds?

\section{Methods}

\section{Site description}

Forests were located in southeastern Michigan, USA $\left(43^{\circ} 8^{\prime} 30^{\prime \prime} \mathrm{N}\right.$ and $82^{\circ} 34^{\prime} \mathrm{W}$; Fig. 1). These forests have complex histories involving extensive late-19th-century logging, burning following logging operations (Williams 1989), land-use stabilization in the early 20th century as widely dispersed and often pastured forest fragments (10-15\% of landscape), and subsequent old field forest reversion that increased forest land cover to its present $17 \%$ (Whitney and Somerlot 1985, Williams 1989, Leatherberry and Spencer 1996). Currently, forests persist as fragments nested within an agricultural-suburban matrix (17 km from a large city) and are connected to varying degrees by natural linear strips of trees (fencerows). Topography is flat and fragments occur along an end moraine, composed of fine-textured, rich, till soils. Sugar maple (Acer saccharum) and American beech (Fagus grandifolia) dominate canopies in mature forests, with eastern hemlock (Tsuga canadensis) and yellow birch (Betula alleghaniensis) in low abundance (see Barnes and Wagner [1981] for species authorities).

Across a $14-\mathrm{km}^{2}$ area, five forest fragments (4-8 ha) were selected that were in close proximity $(300-700$ $\mathrm{m})$, yet varied in plant composition. Species lists of all woody plants and the forest layer they occurred in (overstory, understory, sapling, and seedling) had been compiled earlier using full coverage surveys. These surveys involved searching all areas within each fragment using $15 \mathrm{~m}$ wide transects with additional effort expended until no more than one additional species was found in $30 \mathrm{~min}$ (McEuen 2002). The five fragments varied in their history of disturbance as evidenced by variation in fragment size, canopy cover, total basal area, logging index, and proportion of forest recently reverted (Table 1). 


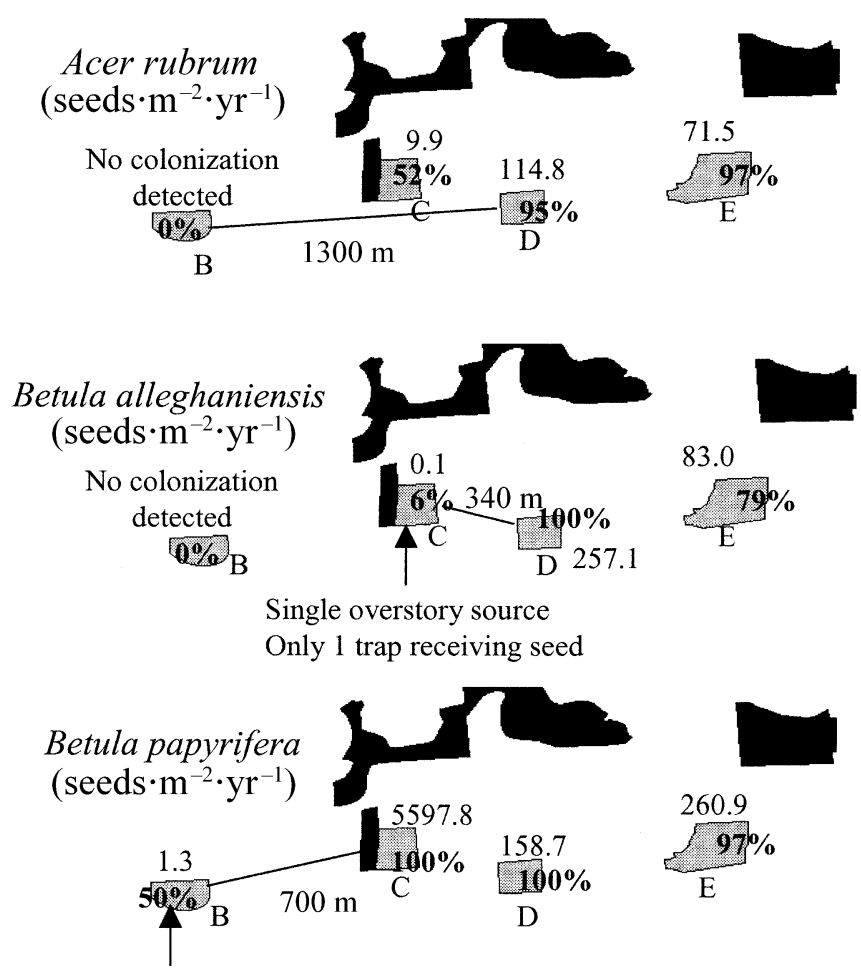

$50 \%$ of traps in unoccupied fragment receive colonizing seed
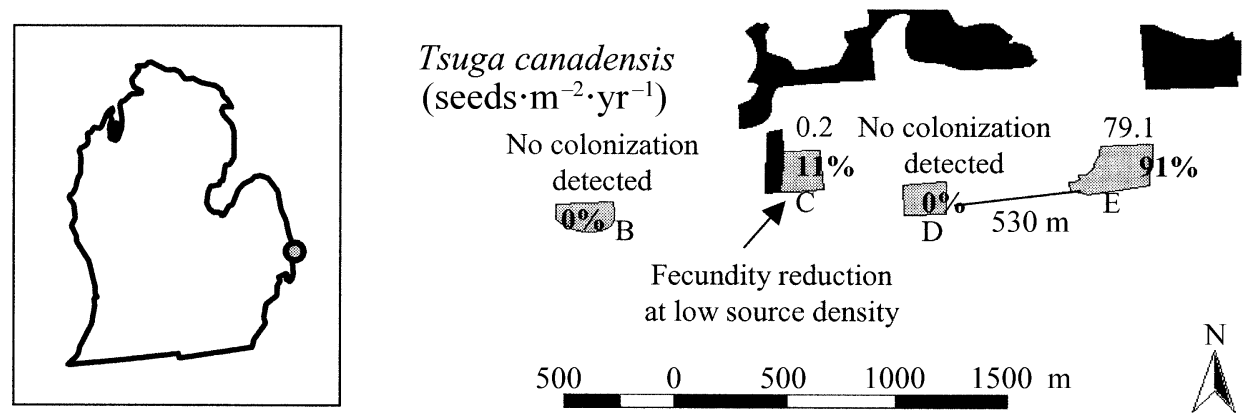

Fecundity reduction

at low source density

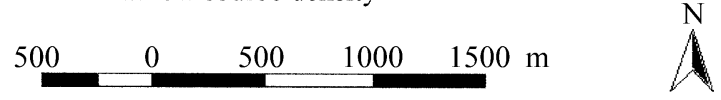

FIG. 1. Study region in Michigan's lower peninsula (inset) and landscape-scale seed rain of four forest trees. Gray shaded areas identify fragments where seed rain was monitored (B-E from west to east). Blackened areas represent nearby forest. Fragment A (not shown) was disjunct from the other four fragments (1.5 km south-southwest of fragment B). Stand seed production (seeds $\cdot \mathrm{m}^{-2} \cdot \mathrm{yr}^{-1}$ ) and percentage of seed traps receiving seed (bold) are shown near each fragment. Shortest distances between fragments (m, edge to edge) are indicated in various panels.

\section{Sampling design}

Adults (hereafter referred to as sources), seedlings, and seed rain were measured at 114 locations across the five fragments (total area $=27 \mathrm{ha}$ ). Sample locations were established systematically throughout each fragment along a staggered 40-m array. Distance to the first line of the array and the first sample point on each line were determined randomly with all subsequent points located at 40-m intervals (Fig. 2). Arrays were oriented approximately north-south in all five fragments (north $355^{\circ}$ for fragments A-C and E, and $354^{\circ}$ for fragment D). Sampling points within each fragment ranged from 17 to 33 , increasing with fragment size
(Table 1). At each point, both forest plots and their associated seed rain were sampled.

Source and seedling composition of forest fragments

At each sampling location, overstory ( $\geq 10 \mathrm{~cm} \mathrm{dbh}$ ) and understory (1-9.9 $\mathrm{cm} \mathrm{dbh}$ ) stem densities were measured within $100-\mathrm{m}^{2}$ circular plots $($ diameter $=11.3$ $\mathrm{m})$. Seedlings $(<1 \mathrm{~m}$ height and $<1 \mathrm{~cm} \mathrm{dbh})$ and saplings ( $\geq 1 \mathrm{~m}$ height and $<1 \mathrm{~cm}$ dbh) were recorded for four $5-\mathrm{m}^{2}$ subplots per plot (pooled for all analyses). Source densities $\left(\mathrm{m}^{2}\right.$ basal area/ha) within each fragment were estimated from overstory data. Source dispersion within fragments was calculated by determin- 
TABLE 1. Summary of forest fragment characteristics and overstory composition.

\begin{tabular}{|c|c|c|c|c|c|}
\hline \multirow[b]{2}{*}{ Measure } & \multicolumn{5}{|c|}{ Fragment } \\
\hline & A & B & $\mathrm{C}$ & $\mathrm{D}$ & $\mathrm{E}$ \\
\hline Size (ha) & 4.28 & 4.65 & 5.48 & 4.57 & 8.13 \\
\hline Canopy cover (\%) & 90.80 & 93.00 & 93.90 & 93.80 & 97.00 \\
\hline Proportion recent forest $\dagger$ & 0.24 & 0.19 & 0.44 & 0.17 & 0.00 \\
\hline Logging index $\ddagger$ & 7.50 & 8.80 & 7.00 & 6.60 & 0.10 \\
\hline History of disturbance§ & high & moderate & high & moderate & low \\
\hline No. of sampling points & 17 & 22 & 21 & 21 & 33 \\
\hline \multicolumn{6}{|l|}{ Basal areas $\left(\mathrm{m}^{2} / \mathrm{ha}\right) \|$} \\
\hline Acer rubrum & 0.12 & 0.00 & 0.77 & 0.95 & 0.68 \\
\hline Acer saccharum & 0.07 & 10.01 & 4.48 & 3.24 & 4.33 \\
\hline Betula alleghaniensis & $0.00^{\mathrm{a}}$ & 0.00 & $0.00^{\mathrm{a}}$ & 0.56 & 0.14 \\
\hline Betula papyrifera & $0.00^{\mathrm{a}}$ & 0.00 & 3.90 & $0.00^{\mathrm{a}}$ & 0.12 \\
\hline Carya cordiformis & $0.00^{\mathrm{a}}$ & 1.93 & 0.64 & 1.14 & 0.31 \\
\hline Fagus grandifolia & 3.82 & 4.27 & 0.43 & 7.45 & 3.48 \\
\hline Fraxinus americana & 4.43 & 1.76 & 1.18 & 3.77 & 6.80 \\
\hline Fraxinus pennsylvanica & 0.72 & 0.06 & 5.44 & 3.33 & 5.51 \\
\hline Malus pumila & 0.60 & $0.00^{\mathrm{a}}$ & $0.00^{\mathrm{a}}$ & $0.00^{\mathrm{a}}$ & $0.00^{\mathrm{a}}$ \\
\hline Ostrya virginiana & 3.95 & 1.56 & 2.04 & 1.26 & 0.64 \\
\hline Prunus avium & 0.61 & $0.00^{\mathrm{a}}$ & 0.00 & 0.00 & 0.00 \\
\hline Prunus serotina & 0.29 & 0.22 & 0.37 & 0.65 & 0.06 \\
\hline Quercus rubra & $0.00^{\mathrm{a}}$ & 0.00 & 0.53 & 0.00 & 1.63 \\
\hline Tilia americana & 3.62 & 0.68 & 0.13 & 0.37 & 4.61 \\
\hline Tsuga canadensis & 0.00 & 0.00 & 0.30 & 0.00 & 0.91 \\
\hline Ulmus americana & 1.00 & 3.64 & 0.63 & 0.62 & 0.44 \\
\hline Ulmus rubra & 0.00 & 0.96 & 0.00 & 0.00 & 0.00 \\
\hline Total basal area $\left(\mathrm{m}^{2} / \mathrm{ha}\right)$ & 19.49 & 25.03 & 21.52 & 23.42 & 31.11 \\
\hline
\end{tabular}

Note: Superscript (a) on zero data indicates species absent from plots but known to be present in the overstory from survey data.

$\dagger$ Proportion of a fragment $<54$ yr old (based on aerial photographs).

\$ Average number of tree stumps located per 10-min survey period.

$\S$ Qualitative assessment based on logging index, forest reversion, canopy cover, total basal area, and abundance of disturbance-associated species (Betula papyrifera, Crataegus spp., Malus pumila, and Prunus spp.).

$\|$ Species with basal areas $>0.5 \mathrm{~m}^{2} / \mathrm{ha}$ in at least one fragment.

ing the proportion of plots with mature individuals. The size class considered mature varied with growth form and included overstory stems (for trees), understory and overstory stems (for understory trees: Carpinus caroliniana, Ostrya virginiana), understory and sapling stems (for vines: Vitis riparia), or seedling and sapling stems (for ground-cover shrub: Rubus spp.).

Source presence in a fragment was determined from initial survey records (McEuen 2002) supplemented by plot data. When sources for seed found in seed traps were not on these lists, fragments were resurveyed exclusively for each species to verify absences. These additional surveys were conducted during the season when each species was most conspicuous (e.g., spring flowering for Eleaganus umbellata). For tree species that had landscape-scale seed exchange (Acer negundo and $B$. papyrifera), areas surrounding fragments were surveyed to determine the nearest potential seed source. This included searching a $700 \mathrm{~m}$ radius area around fragment B for B. papyrifera, and checking reproductive condition for all understory and overstory stems. Seventeen species were included in examinations of landscape-scale seed exchange based on presence in seed rain yet absence from at least one fragment.
Seedling recruitment (number of stems/ha, hereafter recruits) was estimated for each forest plot by combining seedling and sapling counts, saplings of $\mathrm{V}$. riparia were excluded from recruitment estimates because of their reproductive potential. Recruit dispersion was estimated by calculating the proportion of plots within each fragment that contained recruits. Species were excluded from recruitment analyses if recruits were not identified to species (Fraxinus americana, Fraxinus pennsylvanica) or could potentially be reproductive (Rubus spp.).

\section{Seed rain composition of forest fragments}

Seed traps were set at each sampling point. Each trap was a grain bag supported $50 \mathrm{~cm}$ above the ground in a circular wire frame (individual surface area $0.25 \mathrm{~m}^{2}$, design followed Hughes et al. [1988]). Samples were collected from traps at monthly intervals over $2 \mathrm{yr}$ (May 1997 through February 1998, May 1998 through February 1999). Avian scat and regurgitations found on the trap surface were collected separately and frozen, then individually examined for seed under low magnification $(2-10 \times)$. Additional trap contents (litter and seed) was oven dried at $65^{\circ} \mathrm{C}$ for a minimum of 
a) Carpinus caroliniana

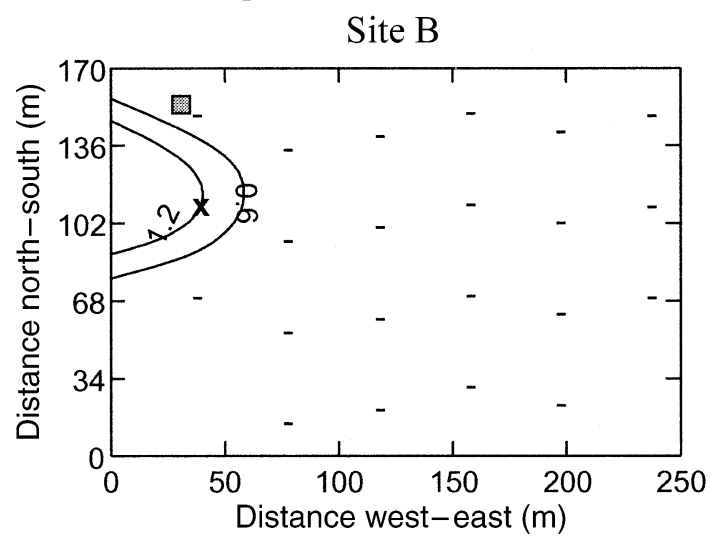

b) Fraxinus pennsylvanica

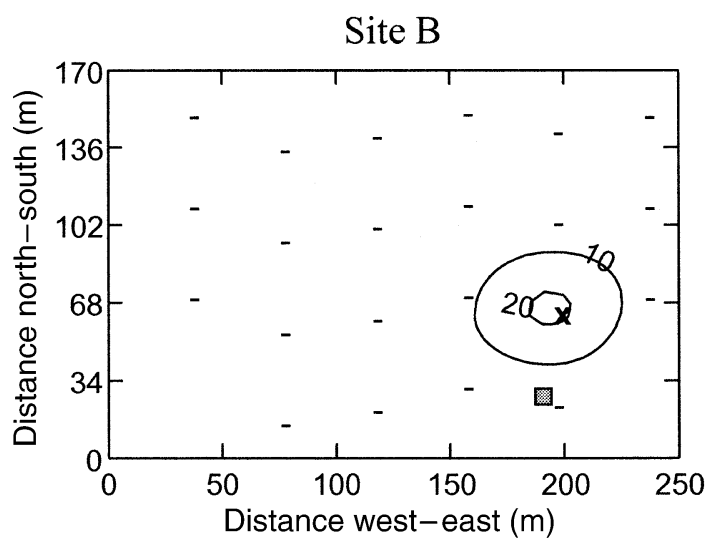

Site A

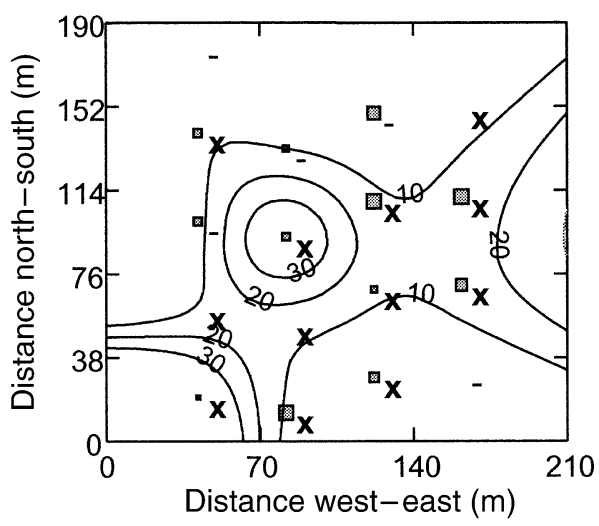

Site C

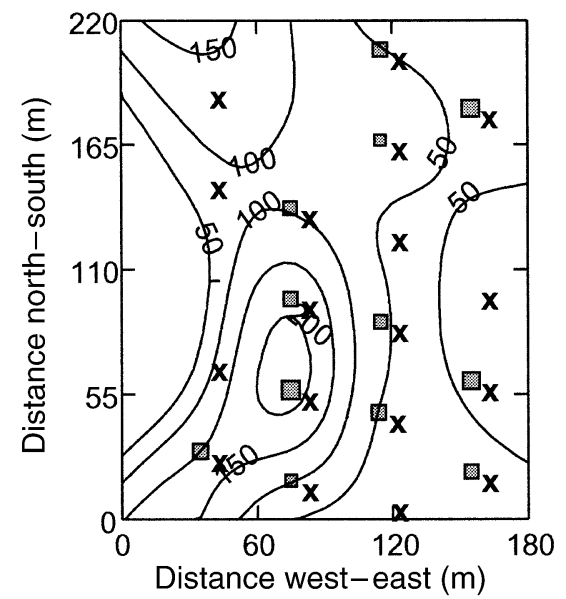

FIG. 2. Seed dispersions and seed abundance for (a) Carpinus caroliniana and (b) Fraxinus pennsylvanica at low and high source densities. Trap locations are indicated by $\times$ or - if they received or failed to receive seed, respectively. Contours indicate seed rain densities (seed $\cdot \mathrm{m}^{-2} \cdot \mathrm{yr}^{-1}$ ). Filled squares display overstory basal area at each trap location (Fraxinus, sized as $\ln \left[\mathrm{cm}^{2}+1\right]$ ) or understory and overstory stem counts (Carpinus, sized as $\ln [$ no. stems +1$]$ ).

24 h. Dried samples were searched using a series of sieves, and all mature woody plant seeds identified and counted (see Methods: Seed characteristics).

Seed production was quantified by standardizing seed counts by seed trap area (number of seeds $\cdot \mathrm{m}^{-2}$ forest floor $\left.\cdot \mathrm{yr}^{-1}\right)$. Tree fecundities were estimated at the stand scale using total seed counts over the two years and stand basal area estimates (number of seeds $\cdot \mathrm{cm}^{-2}$ basal area $\left.\cdot \mathrm{yr}^{-1}\right)$. Seed distributions were quantified by the proportion of traps within a fragment that received seed over the two-year period (hereafter referred to as seed dispersion).

\section{Seed characteristics}

Seed maturity was based on size and condition of the embryo. We recorded whether each seed was aborted (e.g., mature size, but with embryo soft or absent), displayed evidence of insect seed predation (e.g., bore holes present), or was otherwise damaged (e.g., torn seed coat). Seeds were considered potentially viable if they were full, hard, and showed no evidence of predation or other damage. Mean seed mass was calculated from samples of 50 seeds (dried at least $24 \mathrm{~h}$ at $65^{\circ} \mathrm{C}$ ), with higher sample sizes for genera with light seeds (Rubus, Betula, and Tsuga) and a smaller sample for Prunus serotina $(n=38)$. Seed mass for avian-dispersed seed was measured without fleshy pericarp layers. Wind-dispersed seed mass included wings for all species except Tilia americana. Seed mass for Fagus grandifolia was for single nuts.

Counts of potentially viable seeds were used for all seed rain estimates and analyses. Species were excluded from analyses if they were ineffectively trapped (Populus spp.), likely to originate from planting (Pinus sylvestris, Malus pumila), or identification was poor in early seed rain samples (Toxicodendron radicans). Mammal-dispersed seeds (e.g., Quercus) were not included when examining landscape-scale seed exchange because our sampling protocol could not detect dispersal into fragments. 
TABLE 2. Source and seed rain characteristics (mean $\pm 1 \mathrm{SE}$ ) for 17 species of woody plants, averaged across all fragments containing sources $(n)$.

\begin{tabular}{lcccc}
\hline \hline \multicolumn{1}{c}{ Species } & $\begin{array}{c}\text { Mean seed } \\
\text { dispersion } \dagger\end{array}$ & $\begin{array}{c}\text { Dispersal } \\
\text { mode }\end{array}$ & $\begin{array}{c}\text { Seed } \\
\text { mass }(\mathrm{g}) \ddagger\end{array}$ & Seed production $\dagger$ \\
\hline Acer rubrum & $0.76 \pm 0.12$ & wind & $1.36 \times 10^{-2}$ & $50.58 \pm 26.12$ \\
Acer saccharum & $0.62 \pm 0.09$ & wind & $6.57 \times 10^{-2}$ & $12.25 \pm 6.13$ \\
Betula alleghaniensis & $0.64 \pm 0.20$ & wind & $7.70 \times 10^{-4}$ & $96.65 \pm 56.72$ \\
Betula papyrifera & $0.99 \pm 0.01$ & wind & $2.45 \times 10^{-4}$ & $1564.37 \pm 1344.65$ \\
Carpinus caroliniana & $0.50 \pm 0.13$ & wind & $2.36 \times 10^{-2}$ & $5.68 \pm 1.76$ \\
Fagus grandifolia & $0.34 \pm 0.10$ & animal & $2.08 \times 10^{-1}$ & $7.10 \pm 2.13$ \\
Fraxinus americana & $0.71 \pm 0.16$ & wind & $3.63 \times 10^{-2}$ & $22.22 \pm 6.54$ \\
Fraxinus pennsylvanica & $0.73 \pm 0.17$ & wind & $3.07 \times 10^{-2}$ & $59.64 \pm 21.42$ \\
Ostrya virginiana & $0.89 \pm 0.05$ & wind & $2.02 \times 10^{-2}$ & $45.02 \pm 15.58$ \\
Prunus avium & 0.12 & animal & $1.75 \times 10^{-1}$ & 14.82 \\
Prunus serotina & $0.26 \pm 0.08$ & animal & $9.19 \times 10^{-2}$ & $4.00 \pm 2.62$ \\
Rubus spp. & $0.11 \pm 0.06$ & animal & $1.39 \times 10^{-3}$ & $4.74 \pm 1.38$ \\
Tilia americana & $0.52 \pm 0.16$ & wind & $7.84 \times 10^{-2}$ & $33.59 \pm 18.51$ \\
Tsuga canadensis & $0.51 \pm 0.40$ & wind & $1.73 \times 10^{-3}$ & $39.65 \pm 39.44$ \\
Ulmus americana & $0.96 \pm 0.03$ & wind & $5.03 \times 10^{-3}$ & $191.44 \pm 95.00$ \\
Ulmus rubra & 0.64 & wind & $9.58 \times 10^{-3}$ & 26.64 \\
Vitis riparia & $0.41 \pm 0.12$ & animal & $1.58 \times 10^{-2}$ & $9.38 \pm 5.57$ \\
\hline
\end{tabular}

$\dagger$ Variables include seed dispersion (proportion of seed traps receiving seed over $2 \mathrm{yr}$ ), seed production (seeds $\cdot \mathrm{m}^{-2}$ forest floor $\cdot \mathrm{yr}^{-1}$ ), fecundity ( seeds $\cdot \mathrm{cm}^{-2}$ basal area $\cdot \mathrm{yr}^{-1}$ ), source dispersion (proportion of plots with mature individuals), and basal area $\left(\mathrm{m}^{2} / \mathrm{ha}\right)$.

$\ddagger$ Seed mass is oven-dried mass $\left(65^{\circ} \mathrm{C}\right.$ for $\left.>24 \mathrm{hr}, n \geq 38\right)$ and includes wing mass for all wind-dispersed plants except Tilia americana. Avian-dispersed seed mass includes only seed without fleshy pericarp layers.

$\S$ Estimates available from only two of the four sites with sources.

\section{Analyses}

Normality and homogeneity assumptions for parametric tests were assessed using scatter plots, normal probability plots, skewness and kurtosis coefficients, and Lilliefors' test statistics. To examine broad differences in seed dispersion among species, we identified three dispersion categories based on natural data groupings: high seed dispersion $(>70 \%$ traps within a fragment receiving seed), intermediate dispersion (30-70\% of traps receiving seed), and low dispersion $(<30 \%$ of traps receiving seed). To measure and analyze the degree of seed rain clumping, standardized Morisita indices $\left(I_{p}\right)$ were calculated using total seed counts per trap from the 2 -yr period. This index was chosen because of its lack of dependence on densities and sample sizes.

For a subset of 17 woody plants (Table 2), we examined how source density, source dispersion, seed production, dispersal mode, fecundity, and seed mass affected seed dispersion patterns using partial correlation analyses $\left(r_{y x_{1} \cdot x_{2}}\right)$. These 17 species included only those with the highest seed production levels $(\geq 2$ seeds $\cdot \mathrm{m}^{-2} \cdot \mathrm{yr}^{-1}$ in at least one fragment). In three of the five fragments (A, D, and E), seed production was high for a sufficient number of species $\left(\geq 2 \mathrm{seeds} \cdot \mathrm{m}^{-2} \cdot \mathrm{yr}^{-1}\right.$, $\geq 14$ species) to develop multiple linear regression models predicting seed dispersion from source and seed rain characteristics. Analysis of covariance (ANCOVA) was used to examine whether seed dispersion differed for animal- vs. wind-dispersed plants using seed production as a covariate. For these analyses, variables were natural log (seed production, fecundity, seed mass, source density) and arcsine transformed (seed dispersion). Pearson correlation coefficients were used to examine how seed dispersion patterns among fragments varied for individual species as source and seed production levels changed. These within-species analyses were restricted to fragments with sources. Source density and seed production were natural log transformed.

We tested the prediction that seed dispersions and recruit dispersions (seedlings/saplings) were spatially correlated using Fisher's exact tests. These tests were run for the subset of species with sufficient variation in seedling recruitment and seed rain (A. saccharum [fragment E only], C. caroliniana, F. grandifolia, Prunus avium, $P$. serotina, $T$. americana, $V$. riparia). Pearson $\chi^{2}$ tests were used to determine whether data could be pooled across fragments. For the four species that displayed evidence of recruitment limitation (positive associations between seed and seedling distributions), we calculated seed encounter probabilities between each "seed-limited" species and a potential competitor. For these calculations, species pairs were selected that had similar shade tolerances, canopy positions, and response to disturbance. Seed encounter probabilities were estimated within each fragment by dividing the percentage of traps with seed from both species by the total number of traps receiving seed for each individual species.

\section{RESUlts}

\section{General patterns of seed availability}

We collected 98032 mature seeds from 42 species of woody plants over 2 yr. Of these, only Fraxinus nigra failed to produce potentially viable seeds (all 
TABLE 2. Extended.

\begin{tabular}{cccc}
\hline \hline Fecundity $\dagger$ & $\begin{array}{c}\text { Source } \\
\text { dispersion } \dagger\end{array}$ & Basal area $\dagger$ & $n$ \\
\hline $72.07 \pm 24.90$ & $0.16 \pm 0.04$ & $0.63 \pm 0.18$ & 5 \\
$7.58 \pm 5.27$ & $0.48 \pm 0.14$ & $4.43 \pm 1.61$ & 5 \\
$520.28 \pm 65.27 \S$ & $0.03 \pm 0.02$ & $0.35 \pm 0.21 \S$ & 4 \\
$1795.26 \pm 359.29 \S$ & $0.10 \pm 0.09$ & $2.01 \pm 1.89 \S$ & 4 \\
& $0.50 \pm 0.13$ & $3.89 \pm 1.12$ & 5 \\
$1.89 \pm 0.42$ & $0.29 \pm 0.06$ & $3.59 \pm 1.00$ & 5 \\
$5.72 \pm 1.48$ & $0.39 \pm 0.08$ & $3.01 \pm 1.14$ & 5 \\
$23.60 \pm 3.89$ & $0.40 \pm 0.11$ & $1.89 \pm 0.56$ & 5 \\
$22.04 \pm 3.32$ & $0.66 \pm 0.03$ & $0.32 \pm 0.10$ & 5 \\
24.41 & 0.06 & $1.88 \pm 0.93$ & 5 \\
$12.76 \pm 9.18$ & $0.11 \pm 0.02$ & $0.60 \pm 0.31$ & 5 \\
$14.93 \pm 4.38$ & $0.14 \pm 0.08$ & $1.27 \pm 0.60$ & 5 \\
$44.02 \pm 43.30$ & $0.27 \pm 0.09$ & 0.96 & 5 \\
$148.35 \pm 32.50$ & $0.12 \pm 0.03$ & & 5 \\
27.86 & $0.24 \pm 0.05$ & 0.14 & \\
\end{tabular}

aborted). Of the remaining 41 species, analyses were restricted to 37 (see exclusions in Methods, complete species list in McEuen [2002]). All values reported are means \pm 1 SE. Seed production varied between years with a low seed year (mean $=128.7 \pm 16.4$ seeds $\cdot \mathrm{m}^{-2} \cdot \mathrm{yr}^{-1}$ ) followed by a high (mean $=707.1 \pm$ 132.7 seeds $\cdot \mathrm{m}^{-2} \cdot \mathrm{yr}^{-1}$; Wilcoxon Signed Ranks: $Z=8.8$, $P<0.0005, n=112$ ). Tree fecundities varied by three orders of magnitude (Table 2), ranging from 1795 seeds $\cdot \mathrm{cm}^{-2}$ basal area $\cdot \mathrm{yr}^{-1}$ (Betula papyrifera) to $\sim 2$ seeds $\cdot \mathrm{cm}^{-2}$ basal area $\cdot \mathrm{yr}^{-1}$ (Fagus grandifolia, Table 2$)$, and displayed a strong negative relationship to seed mass $(r=-0.91, P<0.0005, n=14$, using average site fecundity estimates [Table 2]). Seed rain was significantly clumped for all species in all fragments $\left(I_{p}\right.$ $>0.5, P<0.05$ ), with avian-dispersed plants displaying the highest degree of clumping (McEuen 2002). The percentage of traps receiving seed within a fragment (seed dispersion) varied considerably between species (Table 2) and across sites (Figs. 2 and 3).

For the majority of species, seed was not widely available within forest fragments. Only three of 37 species (B. papyrifera, Ostrya virginiana, and Ulmus americana) had high seed dispersions within all sites that contained sources (seed in $>70 \%$ of traps in each fragment). In contrast, 22 of 37 species had low seed dispersions $(<30 \%$ of traps receiving seed) across all fragments. The remaining 12 species showed high variability in seed dispersion among fragments, which was associated with changes in source densities and dispersions among sites (Figs. 2 and 3, Table 3). Animaldispersed species were more likely to consistently exhibit low seed dispersions compared to wind-dispersed species $\left(\chi^{2}=18.3\right.$, df $\left.=1, P<0.0005\right)$. This group comprised $86 \%$ of the species in the low seed dispersion category. In contrast, wind-dispersed species comprised only $9 \%$ of the species with low seed dispersions, but $75 \%$ of the species with variable seed dis- persions, and $100 \%$ of the species with consistently high seed dispersions.

\section{Landscape-scale seed exchange}

Landscape-scale seed exchange was detected for only four of 17 species, all associated with disturbed, high-light environments including fencerows (Acer negundo, B. papyrifera, Celastrus scandens, Eleaganus umbellata; all present in fencerow surveys, $n=17$, McEuen 2002). In contrast, no landscape-scale seed exchange was detected for species characteristic of mature forests such as Tsuga canadensis (Fig. 1, McEuen 2002). Closest potential sources for landscape-scale seed rain included fencerows $(A$. negundo, distance $=$ $60 \mathrm{~m}$ ), and residences (B. papyrifera, $7.2 \mathrm{~cm}$ dbh reproductive tree at $360 \mathrm{~m}$ ). Seed arriving from outside of fragments typically colonized a low proportion of traps ( $<10 \%$ for A. negundo, C. scandens, and E. umbellata). Betula papyrifera seed was the exception, successfully colonizing $50 \%$ of the traps in an unoccupied fragment (Fig. 1). This level of seed exchange is likely explained by the tremendous seed source present at 700 $\mathrm{m}$ (Fig. 1, seed production of fragment $\mathrm{C}$ over $2 \mathrm{yr}$ estimated at $6.13 \times 10^{8}$ seeds, see McEuen [2002] for map of all B. papyrifera sources within $700 \mathrm{~m}$ of fragment B).

Broad seed dispersions within fragments were not always associated with landscape-scale seed exchange, indicating a spatial dependency in seed availability (Fig. 1). Specifically, within fragment seed production levels for T. canadensis, Acer rubrum, and Betula alleghaniensis of a magnitude of 79.1 to 257.1 seeds $\cdot \mathrm{m}^{-2} \cdot \mathrm{yr}^{-1}$, successfully saturated those fragments with seed. However, seed from these species was unsuccessful at colonizing unoccupied fragments (Fig. 1). If seed colonization is occurring for these species, it is below the level detectable by our sampling protocol $\left(<0.06-0.12\right.$ seeds $\left.\cdot \mathrm{m}^{-2} \cdot \mathrm{yr}^{-1}\right)$. 

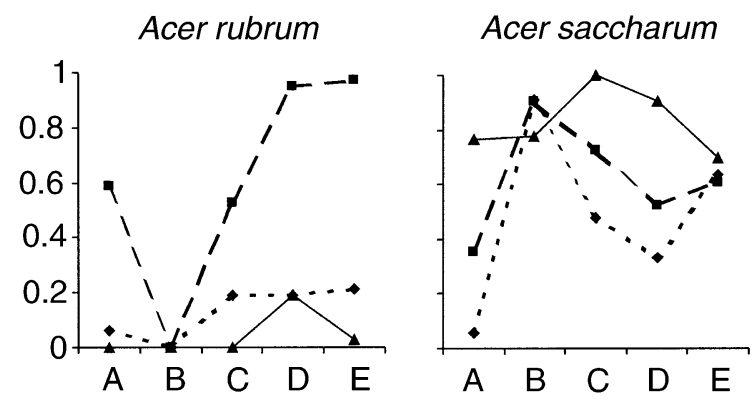

Fagus grandifolia

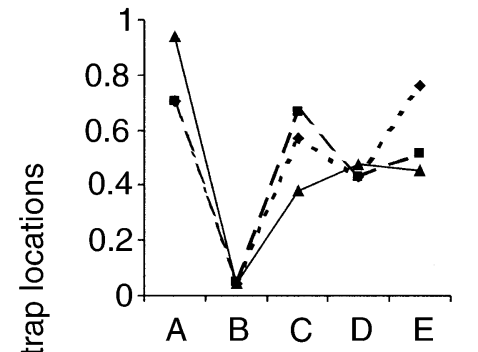

Ostrya virginiana

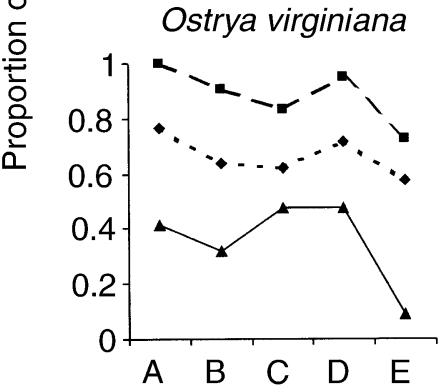

A $B$ C

Tsuga canadensis

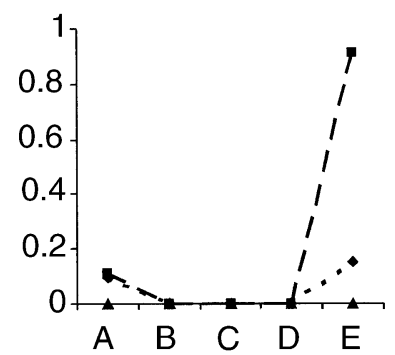

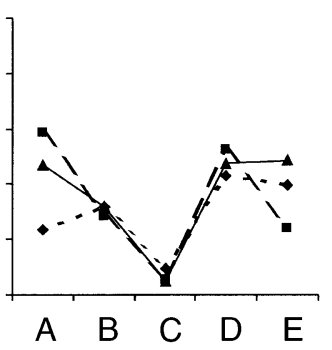

Prunus serotina

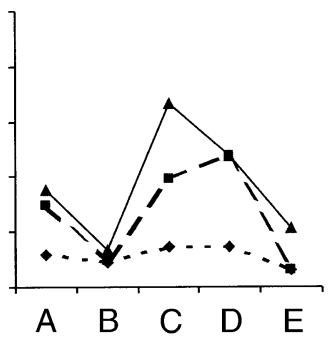

Ulmus americana

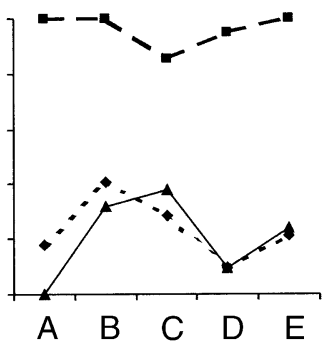

Betula alleghaniensis

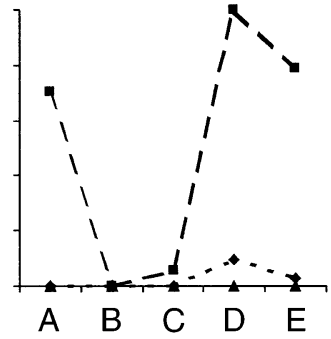

Fraxinus americana

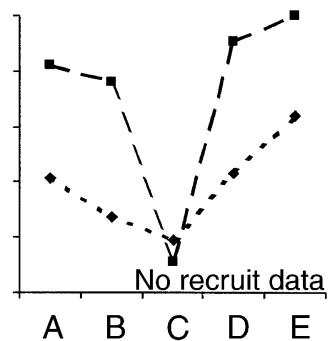

Rubus spp.

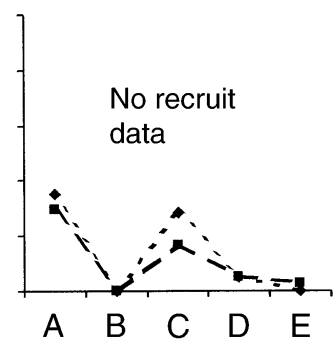

Vitis riparia

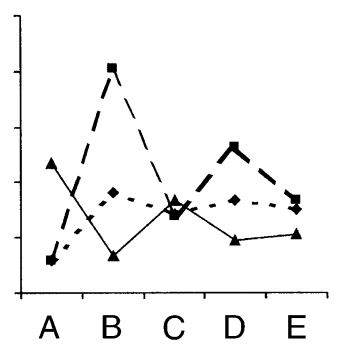

Betula papyrifera

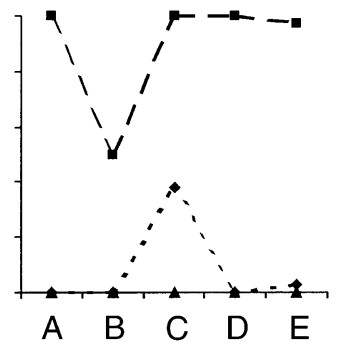

Fraxinus pennsylvanica

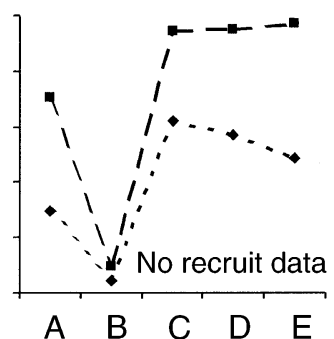

Tilia americana

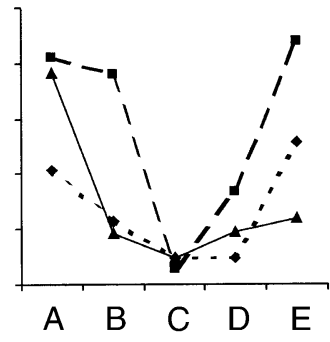

FIG. 3. Source, seed, and seedling/sapling recruit dispersions for 14 woody plant species for the five forest fragments (fragments A-E).

\section{Relationships of seed dispersion to seed} and seed rain characteristics

Differences among species in seed dispersion were related to seed production $(+)$, seed mass $(-)$, source dispersion $(+)$ and source densities $(+)$. Regression models with these variables explained $76-89 \%$ of the variability in seed dispersion among species (adjusted $R^{2}, P<0.005$, McEuen 2002). For two fragments, seed dispersion patterns could be predicted without seed production variables, using only density (basal area) and seed mass (McEuen 2002).
Seed mass, seed production, and source variables.Partial correlation analyses similarly revealed that seed dispersion patterns were produced through an interplay between source availability (densities and dispersions) and seed and seed rain characteristics (seed mass and seed production). As expected given reproductive tradeoffs, light-seeded species had higher seed production and fecundities (Seed production, fragment A, $r=-0.772, n=15, P=0.018$; fragment $\mathrm{D}, r=$ $-0.555, n=14, P=0.039$; fragment $\mathrm{E}$, not significant; Fecundity, fragment A, $r=-0.654, n=10, P=0.040$; 
TABLE 3. Pearson and Spearman rank correlation coefficients (plain text and bold, respectively) between seed dispersion (proportion of traps within a fragment receiving seed over $2 \mathrm{yr}$ ) and seed production (seeds $\cdot \mathrm{m}^{-2}$ forest floor $\cdot \mathrm{yr}^{-1}$ ), source dispersion (proportion of plots with mature individuals), and source densities $\left(\mathrm{cm}^{2}\right.$ basal area $\left./ \mathrm{m}^{2}\right)$ for 14 species of woody plants.

\begin{tabular}{llccc}
\hline \hline \multicolumn{1}{c}{ Species } & $\begin{array}{c}\text { Seed } \\
\text { production }\end{array}$ & $\begin{array}{c}\text { Source } \\
\text { dispersion }\end{array}$ & $\begin{array}{c}\text { Basal } \\
\text { area }\end{array}$ & $n$ \\
\hline Acer rubrum & $0.96^{* *}$ & 0.55 & 0.49 & 4 \\
Acer saccharum & $0.99 * * *$ & $0.93 * *$ & $0.85 *$ & 5 \\
Betula alleghaniensis & $0.99 * * *$ & 0.71 & no est. & 4 \\
Betula papyrifera & 0.25 & 0.26 & no est. & 4 \\
Carpinus caroliniana & $0.93 * *$ & $0.90 * *$ & no est. & 5 \\
Fagus grandifolia & $0.83 *$ & 0.48 & 0.78 & 5 \\
Fraxinus americana & $0.99 * * *$ & $\mathbf{1 . 0 0} *$ & $0.86 *$ & 5 \\
Fraxinus pennsylvanica & $0.98 * * *$ & $0.95 * *$ & $0.99 * * *$ & 5 \\
Ostrya virginiana & 0.77 & $0.94 * *$ & 0.77 & 5 \\
Prunus serotina & 0.75 & $0.96 * *$ & $0.89 * *$ & 5 \\
Rubus spp. & 0.30 & $0.97 * *$ & no est. & 5 \\
Tilia americana & $0.93 * *$ & $\mathbf{0 . 9 8} * .92 * *$ & 5 \\
Ulmus americana & $\mathbf{0 . 8 9}$ & $-\mathbf{0 . 1 5}$ & 0.35 & 5 \\
Vitis riparia & $\mathbf{1 . 0 0 *}$ & $\mathbf{0 . 9 2}$ & no est. & 5 \\
\hline
\end{tabular}

Notes: Coefficients were calculated across all sites with sources $(n)$. Seed production and source density were ln-transformed. Spearman rank correlation coefficients were substituted when relationships appeared nonlinear.

$* P<0.1$; ** $P<0.05$; *** $P<0.005$.

fragment $\mathrm{D}, r=-0.903, n=10, P<0.0005$; fragment E, $r=-0.931, n=11, P<0.0005)$. For any given seed mass (sdms), increases in source density and dispersion was correlated with increasing seed dispersion (Density, fragment A, $r_{y x \cdot \text { sdms }}=0.90, n=10, P=0.001$; Dispersion, fragment A, $r_{y x \text { sdms }}=0.85, n=10, P=$ 0.004 [trees only]; fragment $\mathrm{D}, r_{y x}$ :sdms $=0.80, n=10$, $P=0.009$ [trees only]; fragment E, $r_{y x \cdot \text { sdms }}=0.65, n$ $=14, P=0.017)$. At any given source density, increasing seed mass was negatively correlated with seed dispersion (fragment A, $r_{y x \cdot \text { ba }}=-0.931, n=10, P<$ 0.0005 ; fragment D, $r_{y x \cdot \text { ba }}=-0.907, n=10, P=0.001$; fragment $\mathrm{E}, r_{y x \cdot \mathrm{ba}}=-0.573, n=11, P=0.083$ ). As these correlations suggest, heavy-seeded species required greater source densities to saturate sites with seed. Specifically, high seed dispersions $(>70 \%)$ were observed for light-seeded species (Betula spp.) when $<4 \%$ of plots contained adults and at adult densities below $0.15 \mathrm{~m}^{2}$ basal area/ha, however, high seed dispersions for heavy-seeded species (A. rubrum, Fraxinus spp., Tilia americana) were only observed when more than $19 \%$ of plots contained adults and densities were greater than 0.7 basal area/ha.

Dispersal mode.-Animal-dispersed plants exhibited spatially restricted seed dispersions in contrast to the wide-spread seed dispersions of wind-dispersed species (Table 2; fragment $\mathrm{A}$, mean $_{\text {wind }}=0.77 \pm 0.07$, $n_{\text {wind }}=10$, mean $_{\text {animal }}=0.28 \pm 0.09, n_{\text {animal }}=5$; fragment $\mathrm{D}$, mean $_{\text {wind }}=0.80 \pm 0.08, n_{\text {wind }}=10$, mean $_{\text {animal }}$ $=0.39 \pm 0.17, n_{\text {animal }}=4$; fragment $\mathrm{E}, \operatorname{mean}_{\text {wind }}=0.85$ $\pm 0.05, n_{\text {wind }}=11$, mean $_{\text {animal }}=0.20 \pm 0.09, n_{\text {animal }}=$ $3)$. In two of the three sites, these differences in seed dispersions between dispersal vectors remained significant after adjusting for the higher seed production lev- els of wind-dispersed species (ANCOVA; fragment A, $P=0.011$; fragment E, $P=0.026)$.

Within-species variation.-The same variables affected the variability of seed dispersion within species as affected variability among species: dispersions increased as sources were more broadly distributed, had higher densities, and produced more seeds (Figs. 2 and 3 , Table 3). Highly fecund, light-seeded species such as $B$. papyrifera, were notable exceptions to this generalization, exhibiting well-dispersed seed dispersions throughout all fragments regardless of source densities (Fig. 3, Table 3). In contrast, seed dispersions for many heavy-seeded, wind-dispersed species became severely restricted when their sources were poorly dispersed ( $A$. saccharum, Carpinus caroliniana, $F$. americana, $F$. pennsylvanica, T. americana; Figs. 2 and 3).

\section{Relationships of seed rain to seedling and sapling recruitment}

Seed rain composition differed strongly from that of the seedling, sapling, and understory layers (McEuen 2002). Many species that frequently dominated the seed rain had few to no recruits (B. papyrifera, B. alleghaniensis, U. americana, and T. canadensis; Fig. 3). In contrast, species with low contributions to the seed rain often had high levels of recruitment and frequently increased in dominance between the seedling and understory layers ( $F$. grandifolia, $C$. caroliniana, and Acer saccharum, McEuen 2002). For C. caroliniana, $T$. americana, and $V$. riparia, recruitment densities (stems/ha) increased across fragments as seed production increased ( $n=5$, McEuen 2002). Seed dispersion was positively correlated to dispersion of recruits for 
TABLE 4. Seed encounter probabilities over two years within five fragments (A-E) for four species pairs each including one species displaying evidence of seed limitation (second species in each pair).

\begin{tabular}{|c|c|c|c|c|c|c|}
\hline \multirow[b]{2}{*}{ Competitive pair } & \multicolumn{5}{|c|}{ Fragment } & \multirow[b]{2}{*}{ Mean $\pm 1 \mathrm{SE}$} \\
\hline & A & B & $\mathrm{C}$ & $\mathrm{D}$ & $\mathrm{E}$ & \\
\hline Ostrya encounters Carpinus & $71 \%(17)$ & $5 \%(20)$ & $80 \%(15)$ & $45 \%(20)$ & $46 \%(24)$ & $49 \pm 13 \%$ \\
\hline Carpinus encounters Ostrya & $100 \%(12)$ & $100 \%(1)$ & $100 \%(12)$ & $100 \%(9)$ & $65 \%(17)$ & $93 \pm 7 \%$ \\
\hline Acer saccharum encounters Fagus & $67 \%(6)$ & $30 \%(20)$ & $7 \%(14)$ & $27 \%(11)$ & $30 \%(20)$ & $32 \pm 10 \%$ \\
\hline Fagus encounters Acer saccharum & $40 \%(10)$ & $100 \%(6)$ & $100 \%(1)$ & $27 \%(11)$ & $75 \%(8)$ & $68 \pm 15 \%$ \\
\hline Acer rubrum encounters Tilia & $80 \%(10)$ & & $11 \%(9)$ & $30 \%(20)$ & $88 \%(32)$ & $52 \pm 19 \%$ \\
\hline Tilia encounters Acer rubrum & $57 \%(14)$ & & $100 \%(1)$ & $86 \%(7)$ & $97 \%(29)$ & $85 \pm 10 \%$ \\
\hline$P$. serotina encounters $P$. avium & $40 \%(5)$ & $0 \%(3)$ & & & & $20 \%$ \\
\hline$P$. avium encounters $P$. serotina & $100 \%(2)$ & no hits & & & & $100 \%$ \\
\hline
\end{tabular}

Notes: Probabilities are the percentage of traps with seed of both species out of all traps containing seed for a given species [total $(x$ and $y) /$ total $(y)$ is probability species $y$ encounters species $x$ ]. Numbers in parentheses are the number of traps receiving seed for each species $(n)$. Probabilities were only calculated for fragments containing mature individuals of both species.

C. caroliniana and Prunus serotina and negatively correlated for $V$. riparia $(n=5$, McEuen 2002).

Establishment conditions appear to limit seedling/ sapling distributions of many species at least within some fragments. Several species had restricted recruit dispersions despite widespread seed dispersions (e.g., A. rubrum, O. virginiana, and $U$. americana, Fig. 3). The most extreme examples of establishment limitation were for B. alleghaniensis, B. papyrifera, and T. canadensis which had no seedling or sapling recruits present at any site, despite widely available seed (Fig. 3). Only Acer saccharum exhibited a pattern of recruitment dispersion suggestive of inadequate seed rain sampling, with recruits showing broader dispersions than seed (Fig. 3); high seed abortion over the study period likely accounts for this deviation.

Seven species had sufficient variation in seed and recruit dispersions to test for associations between seed and seedling/sapling presence at each sampling point (A. saccharum, $P$. serotina, V. riparia, and species listed below). Of these, four displayed evidence of seed limitation, with recruit presence significantly associated with presence of seed (Fisher's exact tests: $T$. americana, recruitment percentage with seed $\left(R_{\mathrm{s}}\right)=$ $28 \%$, recruitment percentage without seed $\left(R_{\mathrm{ws}}\right)=8 \%$, $n=95, P=0.009 ; F$. grandifolia, $R_{\mathrm{s}}=76 \%, R_{\mathrm{ws}}=$ $18 \%, n=114, P<0.0005 ;$ C caroliniana, $R_{\mathrm{s}}=59 \%$, $R_{\mathrm{ws}}=18 \%, n=95, P<0.0005 ;$ Prunus avium, $R_{\mathrm{s}}=$ $\left.50 \%, R_{\mathrm{ws}}=0 \%, n=39, P=0.051\right)$.

\section{Seed encounter probabilities for \\ "seed-limited" species}

Seed encounter probabilities were calculated for four species pairs, each containing a species that displayed evidence of seed limitation (Table 4). For all four species pairs, the "seed-limited" species had higher average encounter probabilities than its competitive counterpart (i.e., seeds of "seed-limited" species were more likely to encounter their potential competitor than their competitors' seeds were to encounter them, Table 4). To a large extent, lower seed dispersions for "seed- limited" species accounted for these differences. Seed from "seed-limited" species tended to colonize a low number of traps and encountered their competitive counterpart in most. In contrast, their competitors spread their seed across many traps, and by doing so frequently colonized traps where the "seed-limited" species were absent (Table 4).

\section{Discussion}

As predicted, seed dispersion patterns within temperate northern hardwood forest fragments were spatially restricted. In general, seed was poorly dispersed throughout fragments and seed exchange between fragments was low. For a subset of species, presence of seed at a location was predictive of seedling/sapling presence providing evidence of seed limitation. Species with heavier seeds, and with animal-dispersed seeds, were the most likely to show evidence of seed limitation with seed available at few locations, and significant correlations between seeds and recruits. By examining seed encounter probabilities for species that should be strong competitors in similar environments, we found that seed from these species often fails to simultaneously colonize locations. Our study was conducted over a relatively brief period, yet found strong relationships between patterns of available seed and recruitment distributions. This suggests recruitment limitation (specifically seed limitation) plays a significant role in the dynamics of temperate forests. Long duration studies at similar spatial scales will help further determine the complex dynamics between shifting seed distributions, establishment opportunities, and recruitment. Our two-year study provides additional evidence that such spatially and temporally extensive studies are worth the extensive effort they require (Cain et al. 2000, Bruna 2003). If these studies are conducted in fragmented landscapes, they would have the additional benefit of providing critical data on long-distance dispersal, which we have shown can be studied empirically. 


\section{Forests in fragmented landscapes: landscape-scale seed exchange}

Seed availability can be a limiting factor for most species at larger spatial scales. Even species that were capable of saturating individual fragments with seeds when present at low densities failed to effectively colonize neighboring fragments which lacked their own seed sources. Seed could be arriving in these unoccupied fragments but at densities far too low to detect with our sampling effort. However, the failure to detect colonizing seed for these species even in good seed years demonstrates that large areas within fragments fail to receive seed over a 2 -yr period and therefore, species may miss establishment opportunities. Seed that did colonize fragments from the surrounding matrix were exclusively from disturbance-associated species including one exotic. Forest fragments may therefore confront what Janzen (1986) has called an "eternal external threat," as seed inputs from a human-modified matrix affect their composition and, potentially, their dynamics. Because landscape-scale seed exchange was greater for an early-successional tree (Betula papyrifera) than for mid- or late-successional trees (Acer rubrum, Betula alleghaniensis, Tsuga canadensis), there is the potential for forest succession to be delayed or modified as fragments increase in isolation. More data are needed at this spatial scale from a variety of landscapes to determine the generality of this pattern and prediction.

\section{Variation in seed dispersion and seed limitation among species}

Consistent with longer term studies at smaller spatial scales (Clark et al. 1998), evidence of restricted seed dispersions and seed limitation was greatest for species with heavier seed mass and with animal dispersal vectors. For wind-dispersed species, species can saturate fragments with seeds in one of two ways: either by producing large numbers of light seeds that saturate sites even at low source densities or by achieving high source densities and dispersions throughout a fragment. When their source densities were low, heavy-seeded, wind-dispersed species often failed to saturate fragments with seeds and a subset showed evidence of seed limitation ( $C$. caroliniana, T. americana). The failure of animal-dispersed seed (primarily bird-dispersed) to arrive at a high proportion of traps may be due to biased foraging and perching decisions made by birds. Several studies have documented preferential foraging of frugivores in gaps and higher seed deposition beneath perches (e.g., McClanahan and Wolfe 1987, Malmborg and Wilson 1988). Combined, these results suggest that seed mass and dispersal vector are factors that are predictive in determining the extent of seed limitation experienced by species in temperate forests. Experimental seed additions in this same study system for Lindera benzoin, a heavy-seeded, bird-dispersed shrub, confirm seed limitation is occurring across spatial scales (McEuen 2002). Recent reviews on seed addition experiments also suggest seed limitation is more likely for heavy-seeded species (Moles and Westoby 2002).

\section{Recruitment limitation in temperate forest fragments}

Consistent with Clark et al. (1998), we found establishment conditions limit recruitment for many species, with few or no seedling/sapling recruits found across sites despite abundant seed rain. However, recruitment limitation (specifically seed limitation) may be occurring for a subset of species, those with heavy seed mass or animal-dispersed seeds, or at specific sites where species occur at low densities. Patterns of seed and seedling co-occurrence are suggestive of seed limitation for C. caroliniana, Fagus grandifolia, T. americana, and Prunus avium. This, coupled with the fact that $C$. carolinana and $F$. grandifolia increase in dominance in successive forest layers (from seed, to sapling, understory and overstory), makes "winning by forfeit" a compelling scenario (sensu Hurtt and Pacalla 1995). Seed encounter probabilities were consistent with the idea that seeds, and subsequently seedlings and saplings, may occupy some locations because competitors failed to effectively disperse their seed throughout stands. For the four sets of competitive pairs we examined, the "seed-limited" plants within each pair had heavier seeds and lower seed dispersions. Their heavier seeds would likely make them superior competitors for establishment opportunities (Turnbull et al. 1999), but their poor seed dispersions limit the locations where they are present to compete. Their lighter-seeded, higher seed dispersion "competitors" may therefore win some sites by forfeit. Long-term studies examining the interplay of recruitment opportunities (e.g., gap availability) with seed rain patterns are necessary to determine the degree to which seed and seedling recruitment limitation affects patterns of forest composition and diversity within temperate forests. However, our preliminary evidence of recruitment limitation in temperate systems tantalizingly suggests similar mechanisms operate across forest ecosystems whether tropical or temperate.

\section{ACKNOWLEDGMENTS}

Special thanks to D. Adaire, C. Kunisch, D. Pedler, the Trembles, E. Van Haeck, and Cold Spring Farms for the use of their forests. M. Adam, L. Hinz, K. Lombard, and particularly C. McPherson were stellar field assistants. A. Resnicek and Herb Wagner, Jr. provided enthusiastic guidance with seed and plant identification. Comments from D. DeJoode, G. Fowler, L. Hinz, B. Low, G. Paoli, B. Rathcke, M. Steele, and two anonymous reviewers helped greatly improve the final manuscript. Financial support to A. McEuen was provided by an EPA STAR graduate fellowship, Rackham Predoctoral fellowship, and grants from the School of Natural Resources and Environment and Center for the Education of Women at the University of Michigan. Support during manuscript preparation was provided by Wilkes University, Yale University and NSF (DBI-9978807). 


\section{Literature Cited}

Barnes, B. V., and W. H. Wagner. 1981. Michigan trees: a guide to the trees of Michigan and the Great Lakes region. University of Michigan Press Ann Arbor, Michigan, USA.

Bruna, E. 2003. Are plant populations in fragmented habitats recruitment limited? Tests for an Amazonian herb. Ecology 84:932-947.

Cain, M. L., B. G. Milligan, and A. E. Strand. 2000. Longdistance seed dispersal in plant populations. American Journal of Botany 87:1217-1227.

Clark, J. S., B. Beckage, P. Camill, B. Cleveland, J. HilleRisLambers, J. Lichter, J. McLaclan, J. Mohan, and P. Wyckoff. 1999. Interpreting recruitment limitation in forests. American Journal of Botany 86:1-16.

Clark, J. S., and Y. Ji. 1995. Fecundity and dispersal in plant populations: implications for structure and diversity. American Naturalist 146:72-111.

Clark, J. S., E. Macklin, and L. Wood. 1998. Stages and spatial scales of recruitment limitation in southern Appalachian forests. Ecological Monographs 68:213-235.

Curran, L. M., and C. O. Webb. 2000. Experimental tests of the spatiotemporal scale of seed predation in mast-fruiting Dipterocarpaceae. Ecological Monographs 70:129-148.

Dalling, J. W., H. C. Muller-Landau, S. J. Wright, and S. P. Hubbell. 2002. Role of dispersal in the recruitment limitation of neotropical pioneer species. Journal of Ecology 90:714-727.

Ehrlen, J., and O. Eriksson. 2000. Dispersal limitation and patch occupancy in forest herbs. Ecology 81:1667-1674.

Hubbell, S. P., R. B. Foster, S. T. O'Brien, K. E. Harms, R. Condit, B. Wechsler, S. J. Wright, and S. Loo de Lao. 1999. Light-gap disturbances, recruitment limitation, and tree diversity in a Neotropical forest. Science 283:554-557.

Hughes, J. W., T. J. Fahey, and B. Browne. 1988. A better seed and litter trap. Canadian Journal of Forest Research 17:1623-1624.

Hurtt, G. C., and S. W. Pacala. 1995. The consequences of recruitment limitation: reconciling chance, history and competitive differences between plants. Journal of Theoretical Biology 176:1-12.

Janzen, D. 1986. The eternal external threat. Pages 286-303 in M. E. Soulé, editor. Conservation biology: the science of scarcity and diversity. Sinauer Associates, Sunderland, Massachusetts, USA.

Leatherberry, E. C., and J. S. Spencer. 1996. Michigan forest statistics, 1993. USDA Forest Service, North Central Experimental Station, St. Paul, Minnesota, USA.

Malmborg, P. K., and M. F. Willson. 1988. Foraging ecology of avian frugivores and some consequences for seed dispersal in an Illinois woodlot. Condor 90:173-186.

McClanahan, T. R., and R. W. Wolfe. 1987. Dispersal of ornithochorous seeds from forest edges in central Florida. Vegetatio 71:107-112.

McEuen, A. 2002. Seed dispersal and distributions of woody plants across temperate forest fragments. Dissertation. University of Michigan, Ann Arbor, Michigan, USA.

Moles, A. T., and M. Westoby. 2002. Seed addition experiments are more likely to increase recruitment in largerseeded species. Oikos 99:241-248.

Nathan, R., and H. C. Muller-Landau. 2000. Spatial patterns of seed dispersal, their determinants and consequences for recruitment. Trends in Ecology and Evolution 15:278-283.

Ribbens, E., J. A. Silander, and S. W. Pacala. 1994. Seedling recruitment in forests: calibrating models to predict patterns of tree seedling dispersion. Ecology 75:1794-1806.

Turnbull, L. A., M. J. Crawley, and M. Rees. 2000. Are plant populations seed-limited? A review of seed sowing experiments. Oikos 88:225-238.

Turnbull, L. A., M. Rees, and M. J. Crawley. 1999. Seed mass and the competition/colonization trade-off: a sowing experiment. Journal of Ecology 87:899-912.

Whitney, G. G., and W. J. Somerlot. 1985. A case study of woodland continuity and change in the American midwest. Biological Conservation 31:265-287.

Williams, M. 1989. Americans and their forests: a historical geography. Cambridge University Press, Cambridge, UK. 